\title{
Gamma Shooting of the Territory of Municipal Landfill of the Dushanbe City
}

\author{
D. A. Abdushukurov ${ }^{1, *}$, G. B. Anvarova ${ }^{2}$, D. V. Bondarenko ${ }^{3}$, B. N. Mamadaliev $^{4}$, D. F. Stotsky ${ }^{5}$ \\ ${ }^{1}$ Leading researcher, Physical Technical institute of Academy of Sciences, Dushanbe, Tajikistan \\ ${ }^{2} \mathrm{PhD}$ student, Physical Technical institute of Academy of Sciences, Dushanbe, Tajikistan \\ ${ }^{3}$ Physical Technical institute of Academy of Sciences, Dushanbe, Tajikistan \\ ${ }^{4}$ Director of NGO «Tabiati Toza», Dushanbe, Tajikistan \\ ${ }^{5}$ Committee on Emergency Situations, Dushanbe, Tajikistan
}

\begin{abstract}
The rearrangement of Municipal landfill of Dushanbe city has begun; in this connection the gamma and neutron shooting of territory of landfill has been made. The landfill territory has been divided into 128 routes, and it has been conducted 5691 measurements of gamma background. The gamma background in territory is defined by background from environing soils $0.18 \pm 0.02 \mu \mathrm{Zv} / \mathrm{h}$ and background from low-active wastes $0.11 \pm 0.02 \mu \mathrm{Zv} / \mathrm{h}$. During conducting gamma shooting the ownerless gamma source Cesium-137, with equivalent dose rate $40 \mu \mathrm{Zv} / \mathrm{h}$, has been detected. For localization and source extraction specialists of Committee on emergency situations under government RT and Agency on Radiation and Nuclear Sa fety at Academy of Sciences RT have been invited. Fluency of neutrons on surface does not exceed background values and that testifies about absence of neutron sources.
\end{abstract}

Keywords Gamma Shooting, Neutron Shooting, Gamma’S Background, an Ownerless Radioactive Source, Municipal Landfills

\section{Introduction}

After collapse of the USSR the centralized monitoring system over storage and disposal of radioactive sources in Tajikistan has been destroyed. And only after 11 years, in 2003 the Agency on Control for Radiation and Nuclear Safety has been created. During the civil war years and after it there could be events of losses or illegal disposal of radioactive nuclear sources at the Republic factories. For the purpose of search of ownerless radioactive sources IAEA financed the project of the Agency on Radiation and Nuclear Safety.

Recently the decision on rearrangement of Municipal landfill (ML) of Dushanbe city was made. W ithin the limits of rearrangement it is supposed to carry out a soil covering of a surface of a landfill dump. Before realization of these works there was a necessity of conducting gamma and neutron shooting of a surface of a landfill, for the purpose of detection of illegally buried of ownerless sources.

ML of Dushanbe city is located in its southeast part, in 12 $\mathrm{km}$ from the centre and $2 \mathrm{~km}$ from a route of Dushanbe Vahdat, fig. 1. The relief of territory of a dump represents complex undulating system with comparative deep ravine,

* Corresponding author:

abdush@tajik.net (D.A.Abdushukurov)

Published online at http:/journal.sapub.org/je

Copyright @ 2012 Scientific \& Academic Publishing. All Rights Reserved sometimes with steep slopes, with a grade from $5-10^{\circ}$ to $25-30^{\circ}$. The territory is located at altitudes $870-930 \mathrm{~m}$ above sea level. Landfill exp loitation has begun in 1977. The landfill total area makes more than 20 hectares, the maximu m depth of a body of landfill exceeds $30 \mathrm{~m}$. Territory of landfill has no accurately certain boundary lines and fences. The landfill surface was not covered with a ground for many years, therefore all working zone for today is accessible.

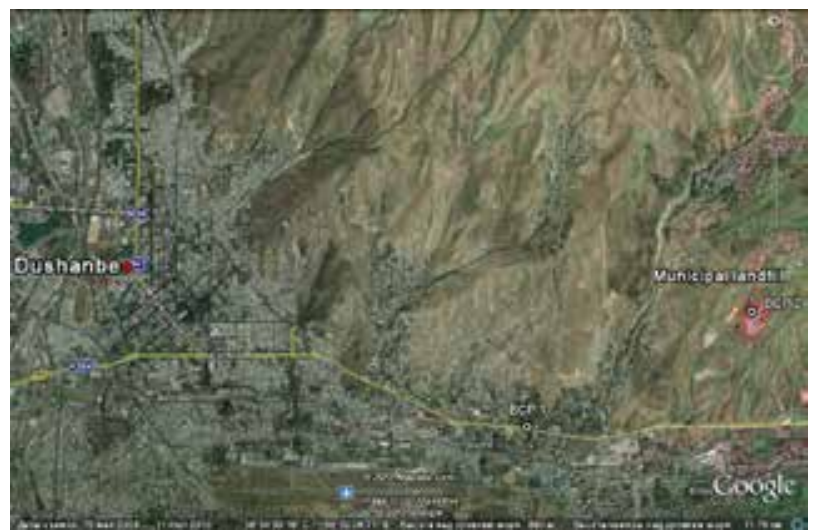

Figure 1. The map shows the localization of Municipal landfill in the southeast of Dushanbe. The map was made by means of program Google Earth [6]

The present work is dedicated to discussion of results of gamma and neutron shooting made on landfill territory. As a result of work the ownerless gamma quanta source has been 
detected. For the source extraction specialists of Committee on Emergency Situations under Government of Republic of Tajikistan and Agency on Nuclear and Radiation safety at Academy of Sciences have been invited. The taken source has been directed to laboratory of Agency for identification and the subsequent disposal.

\section{Method of Conducting of the Gamma Shooting}

Preliminary reconnaissance investigations of the ML were carried out before beginning of works. With shuttle route landfill and its natural complex were familiarized, correctness and conformity of a modern situation with topographic maps were checked. Landfill contours were plotted, wind rose beam directions defined.

Two basic monitoring points (BMP), for the monitoring over correctness of work of dosimeters have been chosen. The first place of BMP was chosen in territory of Physical Technical institute in $4 \mathrm{~km}$ from landfill, the second place was chosen near to a landfill office build ing. Chosen BMPs were noted on a district map. The topographic grid was put on the map-scheme of landfill with step of 5 meters, fig. 2 . The grid has been tied up to outstanding points on locality (electric poles) and fixed in the working notebook. A knot of this topographic grid has been numbered. In an aspect of relief complexity the itineraries for access the measurement points were chosen. The beginning and the end of a grid, a position of monitoring knots on it and coordinate of BMPs were measured by means of the GPS-navigator and were recorded in the notebook.

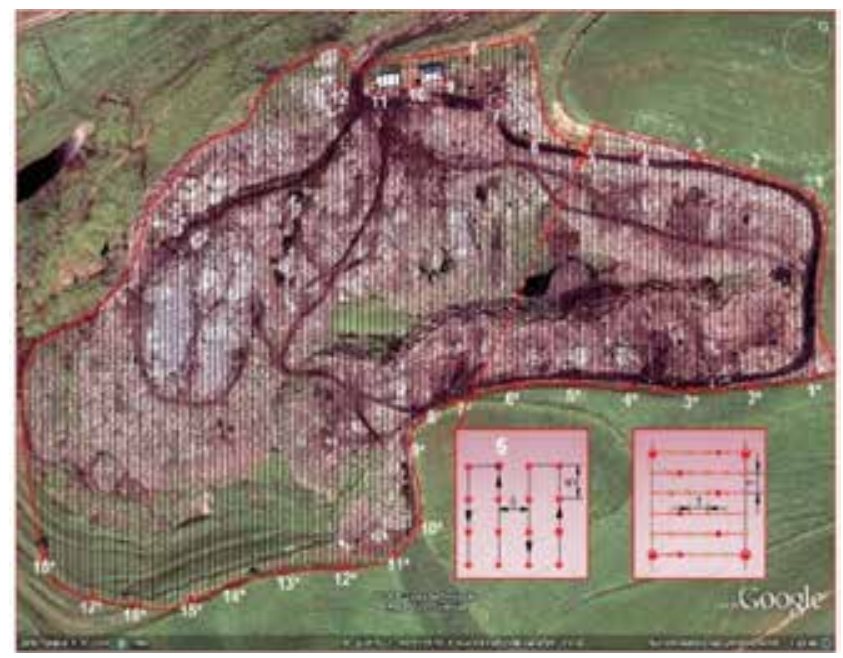

Figure 2. Map of the distribution of itineraries of measurements. The map was made by means of program Google Earth [6]

Dosimeters of type "MKS-A 03" and "LUDLUM 2241-2" were used in-process which was adjusted on an optimum regime accord ing to service manuals of devices.

Before beginning of the work the measurements of an equivalent dose rate (EDR) of gamma background at altitude of 0.1 and 1 meter and fluency of neutrons on two points of
BMP were performed, were thus spent not less than 5 measurements, the obtained data was averaged. Comparis on of measurements were made in the beginning and in the end of the working day, they were correlated among themselves on BMP. Indications of dosimeters did not differ from each other more than on $+/-10 \%$.

Along the chosen routing lines a gamma shooting was performed. Distance between measuring points was choose equal to $5 \mathrm{~m}$. The fixed measurements of gamma background and neutrons intensity (on a point) have been performed in the grid knots. Speed of foot shooting did not exceed 2,0 $\mathrm{km} / \mathrm{hour}$. By conducting gamma shooting continuous audition of noise level in earphones and observation on a scale of dosimeters was performs. Audition of intensity of noise (caused by intensity gamma-background) was made at as much as possible pushed detector. In the course of conducting of the gamma shooting test- check of sensitivity of dosimeters by test source was performed periodically each 2 hours and battery power levels of devices were mon itored.

At measurements in the nodal points the detector of device was placed on distance of 1 meter and performed fivefold measurement of gamma background and neutron's intensity, the data was averaged and registered in the notebook, then the detector was hauled down on distance of 0,1 meter and procedure repeated. At detection of excess gamma background - on $30 \%$ from a natural background careful measurement of radiation intensity in radius of 5 meters was performed. For this purpose the grid broke into sections on 1 meter, and additional measurements and search of an abnormal zone were performed.

\section{Results of Measurements}

During the performed works 5691 measurements of gamma background in the points has been registered. Landfill has been divided into 128 lines of measurements routing lines least of which was 75 meters and the greatest 355 meters. Gamma background on a surface of soils equals $0.18 \pm 0.02 \mu \mathrm{Zv} / \mathrm{h}$, and this background is typical for a Dushanbe city and its neighbourhoods. Background measurements on BMP points have shown similar values, $0.18 \mu \mathrm{Zv} / \mathrm{h}$ near Physical Technical institute and $0.19 \mu \mathrm{Zv} / \mathrm{h}$ near office building of $\mathrm{ML}$, measuring points were placed on distance more than 20 meters from structures.

The wastes on landfill in the basic consist of pieces of polyethylene, glass, paper and rag scraps, and also food wastes. At unloading of wastes from trucks all visible metals (black and colour), polyethylene tare and large plastic products was being collected, for recycling. The remained wastes are slightly radioactive and their gamma background does not exceed $0.11 \pm 0.02 \mu \mathrm{Zv} / \mathrm{h}$, fig. 3 .

Considering the big square of an urban dump - more than 20 hectares, 20 days have been spent for conducting of a field work. Results of measurements are introduced in drawing 4. At measurement the ground roads with background of $0.16-0.20 \mu \mathrm{Zv} / \mathrm{h}$ were clearly visible. Ground roads edged a 
dump boundary line, also there are the inner roads with the raised background presented.

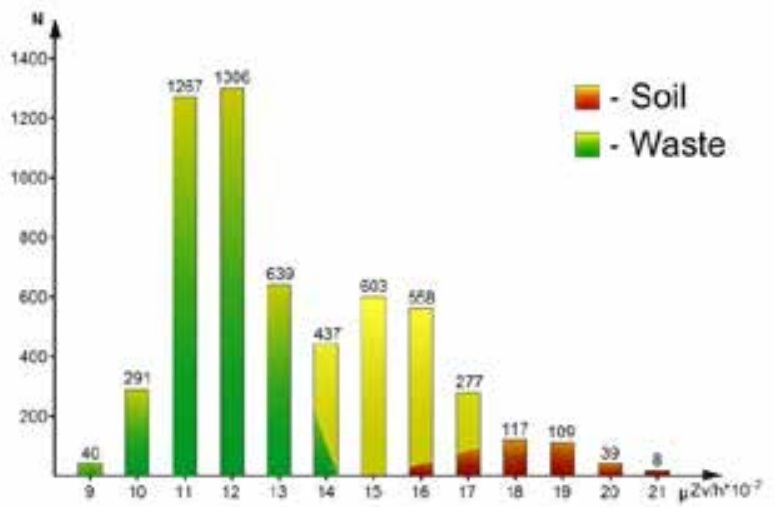

Figure 3. Distribution of gamma background on Equivalent Dose Rate depending on quant ity of measuring points

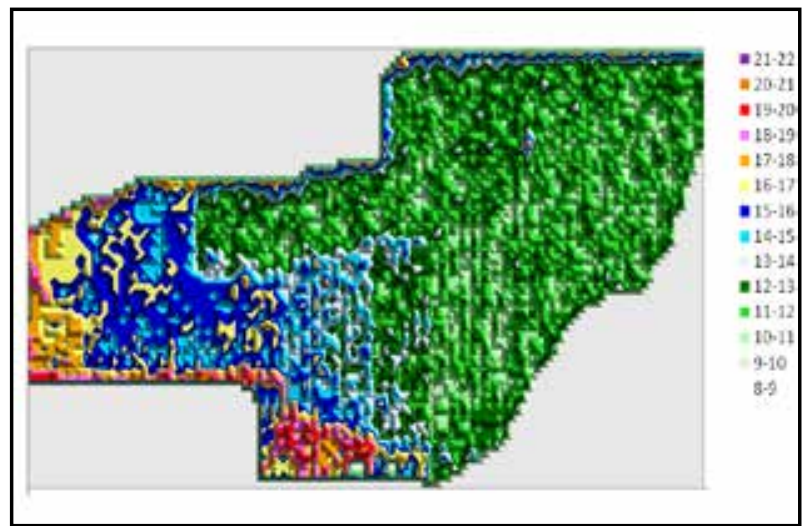

Figure 4. Distribution of gamma background on landfill territory in $\mu \mathrm{Zv} / \mathrm{h} * 10^{-2}$

The landfill is located on a slope of a hill and the thickness of wastes on it varies. On northern slope a thickness of wastes less and does not exceed 3 meters, and the soil shows up in some places. The gamma background on this section equals $0.15-0.18 \mu \mathrm{Zv} / \mathrm{h}$. On a southern slope (located lower) the thickness of wastes in places makes 30 meters, moreover there are no ground roads on this slope. Gamma background on this section was low compared to other places of the landfill and it's equal $0.09-0.13 \mu \mathrm{Zv} / \mathrm{h}$.

On one of the point on the northern section the abnormal zone with EDR more than $1 \mu \mathrm{Zv} / \mathrm{h}$ was detected, the neutron intensity remained constant and did not exceed background values. Detected place has been investigated follow-up, with more fine steps and was revealed the place with EDR more than $10 \mu \mathrm{Zv} / \mathrm{h}$. Discovered place has been recorded by external outstanding points and GPS, fig. 5.

By rules of IAEA detection of a radioactive source of unknown type and activity, is considered as emergency situation. Specialists of Committee on Emergency Situations under the Govern ment of Republic Tajikistan and Agency on Nuclear and Radiation Safety of the Academy of Sciences have been invited to the place. The discovered section has been surrounded. A repetitive measurement of EDR in a finding point by means of devices of the above-stated structures has been performed. Attempt to determine the type of source was made with using the scintillation gamma-ray spectrometer "InSpektor 1000", but it was failed to detect it on-site. Decision to dig out the source was made. The source was placed on depth less than $10 \mathrm{~cm}$ that simplified a problem on its extraction. The taken source represented the metal container of $4 \mathrm{~cm}$ in length and $1 \mathrm{~cm}$ in diameter. EDR in a source surface has equal $40 \mu \mathrm{Zv} / \mathrm{h}$. The source has been disposed in the container and carried out to laboratory of Agency on Nuclear and Radiation Safety. During researches in laboratory it has been found out that the source is gamma emitter of Cs-137.

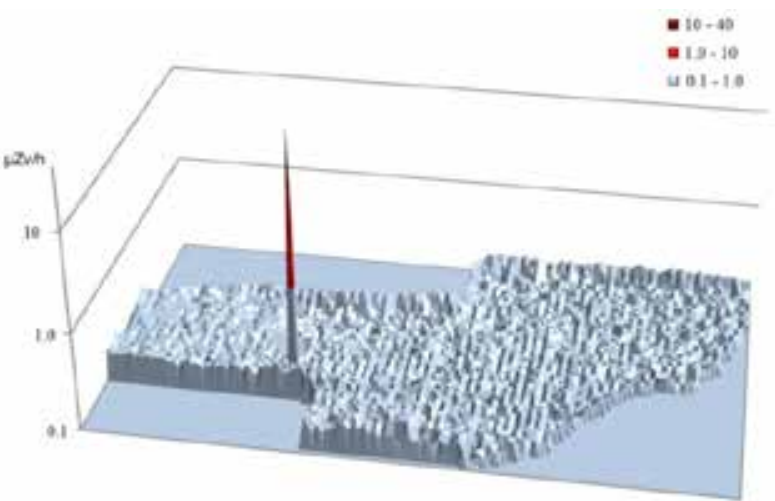

Figure 5. Tridimensional bar graph of distribution gamma background on a surface of landfill. The point matching to the found source is clearly visible

Value of a neutron stream in all territory of a dump did not exceed background values.

\section{Conclusions}

In connection with forthcoming rearrangement of the Municipal landfill of Dushanbe city the gamma and neutron shooting of a surface of landfill has been made. During the performed works 5691 measurements of gamma background in the points has been registered. Landfill has been divided into 128 lines of measurements - routing lines least of which was 75 meters and the greatest - 355 meters. Gamma background of adjoining soils equal $0.18 \pm 0.02 \mu \mathrm{Zv} / \mathrm{h}$ and wastes equal $0.11 \pm 0.02 \mu \mathrm{Zv} / \mathrm{h}$ were measured. Gamma background on a dump varied dependent on these two values and varies with changes of waste thickness too. The neutron background in all territory of a dump did not exceed background values, which testify the absence of disposal of neutron sources.

During shooting the ownerless illegally buried gamma source of Cs-137, with EDR on a surface $40 \mu \mathrm{Zv} / \mathrm{h}$ was detected. For liquidation of the emergency situation specialists of Committee on Emergency Situations under Government of Republic Tajikistan and Agency on Nuclear and Radiation Safety at Academy of Sciences have been invited. The source has been taken, placed in to the container and carried out to laboratory of Agency for identification and the subsequent disposal.

In the conclusion authors express gratitude to specialists of Committee on Emergency Situations under Government 
of Republic Tajikistan and Agency on Nuclear and Radiation Safety of Academy of Sciences of Republic of Tajikistan for the help and participation in process.

\section{REFERENCES}

[1] N.T. Buriev, D.A.Abdushukurov and T.T.Vandergraaf, "Restoration and Assessment of the Extent of Contamination of the National Radioactive Waste Storage and Disposal Centre in Tajikistan,” WM2011 (2011), Phoenix, Arizona, USA.

[2] N.T. Buriev, D.A.Abdushukurov and T.T.Vandergraaf, "Remidiation and Assessment of the National Radioactive Waste Storage and Disposal Site in Tajikistan”, Proceedings of the 14th International Conference on Environmental Remediation and Radioactive Waste Management, ICEM 2011,2011, Reims, France

[3] "The Basic Sanitary Rules of Maintenance of Radiation Safety”, (OSP-2002), 2002, Atomizdat, Moscow (in Russian).

[4] N.T.Buriev, D.A.Abdushukurov, A.A.Dzhuraev, "Methodical Directions for Conducting of Foot Radiation Shooting of Territories and Placements", pub. by Kotra, Dushanbe, 2009, (in Russian).

[5] Juraev A.A., Dzuraev An.A., Davlatshoev T., Passel H.D., "Allocation of connatural and technogenic radioactivity in samples of ground submontane and mountain regions of central Tajikistan”, Springer Science+Business Media B.V.p. 151-165, 2008.
[6] Google Earth: http:// www.google.com/intl/ru/earth/

[7] Kim, J., Walsh, G.J., and King, S., "Lithologic control on naturally occurring radioactivity and ground water chemistry across the Richardson Memorial Contact, central Vermont”: Geological Society of America Abstracts with Programs, v. 37, no. 1, 2005, p. 78.

[8] “Background Radiation Study”, Australian Nuclear Science and Technology Organisation. http://www.arpansa.gov.au

[9] Oak Ridge Institute for Science and Education (ORISE). "Survey Procedures Manual for the Environmental Survey and Site Assessment Program”. Oak Ridge, TN; January 7, 1998.

[10] Oak Ridge Institute for Science and Education. "Revised Verification Survey Plan for Area of Concern 16, Landscape Soil”, Oak Ridge,' TN; May 4,2000a.

[11] Oak Ridge Institute for Science and Education. "Quality Assurance Manual for the Environmental Survey and Site Assessment Program”. Oak Ridge, TN; March 10,2000b.

[12] Oak Ridge Institute for Science and Education. "Laboratory Procedures Manual for the Environmental Survey and Site Assessment Program”. Oak Ridge, TN; June 12,2000c.

[13] L. S. Quindós, et al., "Natural gamma radiation map (MARNA) and indoor radon levels in Spain”, Env. Int., 29, (2004), p. 1091-1096.

[14] NCRP, Environmental Radiation Measurements, National Comity on Radiation Protection, Report \#50, USA, 1976.

[15] Eisenbud M. and Gesell t., "Natural activity, Environmental Radioactivity from Natural, Industrial and Military Sources”, $4^{\text {th }}$ Edition, San Diego, Academic Press, (1997). 